\title{
PENGARUH INSTAGRAM ONLINE STORE, KONFORMITAS DAN IKLAN TELEVISI TERHADAP PERILAKU KONSUMTIF SERTA DAMPAKNYA TERHADAP GAYA HIDUP HEDONIS MAHASISWA
}

\author{
Bambang Setia Wibowo 1 \\ ${ }^{1}$ STIE YKPN Yogyakarta \\ bambang.setia@stieykpn.ac.id
}

\begin{abstract}
This study examined the influence of instagram online store, conformity and television ads to consumptive behavior and its impact to student hedonic lifestyle. This study is the integration of previous studies to determine the effect of simultaneous between variables. Respondents of this study were 142 university students respondents who have used social media instagram for online shopping, have a strong group of friends and know the television ads of fashion products. There are several findings in this study. First, instagram online store has positive influence to the consumptive behavior. Second, conformity has positive effect to consumptive behavior. Third, television ads has no effect to consumptive behavior. Fourth, consumptive behavior has positive effect to student hedonic lifestyle.
\end{abstract}

Keywords: instagram online store, conformity, television ads, consumptive behavior, student hedonic lifestyle

() 2018 JBTI. All rights reserved

Article history : received 23 Des 2017; revised 2 Jan 2018 ; accepted 12 Jan 2018

\section{PENDAHULUAN}

Perkembangan Online Shop atau toko online melalui media internet sudah menjamur di Indonesia, bahkan sudah sangat dikenal baik oleh masyarakat. Berbagai alat atau media komunikasi dan berbagai media sosial telah bermunculan. Media komunikasi yang dimaksud disini khususnya yaitu smartphone. Berbagai jenis media sosial yang memanfaatkan internet yang juga sedang marak digunakan diantaranya facebook, twitter, skype, instagram, line, whatsapp, blackberry messenger, path dan masih banyak lagi jenis media sosial lainnya. Media-media sosial yang kini banyak digunakan tentu lebih menarik karena fitur yang ditawarkan, tak hanya untuk mengirim pesan saja tetapi juga masyarakat dapat berbagi foto, video, musik dan data lainnya melalui media sosial (O'Brien, 2016).

Online shopping atau aktivitas berbelanja online menjadi gaya hidup baru bagi pengguna Internet. Komunikasi terbuka yang sejajar, datar, dan luas telah membuka kemungkinan tidak terbatas bagi komunikasi antar pengguna Internet, yang pada akhirnya juga membuka peluang bagi terjadinya transaksi menjual atau membeli. Platform atau forum jual beli channel yang paling sering digunakan terutama bagi pengguna Internet laki-laki untuk belanja online. Sementara pengguna internet perempuan lebih cenderung memilih situs jejaring sosial yaitu sebesar $50,6 \%$, dan $24 \%$ laki-laki (Hausman dan Siekpe, 2009).

Dalam penelitian ini, penulis akan membahas lebih lanjut mengenai media sosial instagram. Instagram adalah aplikasi gratis untuk berbagi foto yang memungkinkan penggunanya untuk mengambil foto dan selanjutnya berbagi pada layanan jejaring sosial (Zadmehr et al., 2016). Instagram dapat terhubung langsung ke media sosial lainnya seperti facebook dan twitter. Di dalam instagram, pengguna dapat memberikan tanda like dengan simbol love dan juga memberikan 
komentar terhadap foto dan video yang diunggah sendiri atau foto dan video yang diunggah pengguna instagram lain.

Menurut Enrico et al. (2014) dalam kaitannya dengan perilaku konsumtif, menyatakan bahwa tendensi perilaku konsumtif remaja sebagian besar terbentuk dengan melihat dan meniru orang lain dalam konteks sosial. Ini terlihat dari kecenderungan mahasiswa yang cenderung memasuki suatu kelompok maka pengaruh pemberian norma oleh kelompok tersebut akan berdampak pada timbulnya konformitas yang kuat. Kondisi demikian dapat membuat mahasiswa untuk ikut atau lebih menyesuaikan diri dengan norma atau kelompok agar mendapat penerimaan dari kelompok tersebut.

Faktor sosial seperti kelompok referensi, keluarga, serta peran sosial dan status mempengaruhi perilaku konsumen. Kelompok referensi (reference group) yaitu semua kelompok yang mempunyai pengaruh langsung (tatap muka) atau tidak langsung terhadap sikap atau perilaku orang tersebut (Kotler 2009). Lingkungan dalam kelompok sebagai acuan yang sangat berpengaruh pada perilaku serta gaya hidup. Berdasarkan hal ini, jika berkembang dalam suatu konformitas khususnya kelompok yang gemar berbelanja mahasiswi indekost tersebut akan mengikuti perilaku yang terjadi dalam kelompok tersebut.

Kotler (2009) mengatakan bahwa kelompok akan mempengaruhi tiga hal dalam diri seseorang yaitu menghadapkan seseorang pada perilaku dan gaya hidup, mempengaruhi perilaku dan konsep pribadi, serta menciptakan tekanan untuk mematuhi pilihan atau merk suatu produk. Seperti yang diungkapkan oleh Putri (2015), perilaku konsumtif dipengaruhi oleh faktor internal, eksternal dan proses psikologis. Kepribadian, gaya hidup, dan demografi berpengaruh terhadap sikap maupun perilaku konsumtif seseorang. Jenis, cara, dan tingkat mengkonsumsi produk dianggap sebagai bagian dari kepribadian dan gaya hidupnya. Bakat, minat, nilai dan konsep diri merupakan faktor psikologis dalam diri individu yang juga berpengaruh dalam sikap dan perilaku membeli.

Hal ini sesuai dengan Schiffmann dan Kanuk (2004) dalam buku consumer behavior memperjelas bahwa kelompok referensi memiliki pengaruh kuat dikarenakan kelompok referensi ini merupakan tempat bagi individu untu melakukan perbandingan, memberikan nilai informasi dan menyediakan suatu bimbingan ataupun petunjuk untuk melakukan konsumsi.

Iklan televisi mempunyai cakupan jangkauan yang luas dan repetisi yang tinggi serta mampu menampilkan pesan multimedia (suara, gambar dan animasi) yang dapat mempertajam ingatan konsumen terhadap iklan tersebut terlebih terhadap merek dan produk yang diiklankan (Lowrey et al., 2010). Banyak konsumen yang tertarik terhadap suatu produk setelah melihat iklan di televisi. Sebagai contoh, penjualan coca-cola meningkat pesat $41,7 \%$ setelah mengiklankan produk di televisi (Henningsen et al., 2011). Hal ini menunjukkan bahwa, iklan multimedia (suara, gambar, dan animasi) sangat efektif unruk menyampaikan pesan kepada konsumen.

\section{KAJIAN TEORI}

Instagram Online Store berpengaruh terhadap perilaku konsumtif mahasiswa (Che et al., 2017). Pelaku bisnis online mengaku lebih mudah memasarkan produknya melalui Instagram karena sasaran pertama adalah orang yang paling dekat dengannya, bisa juga melalui teman yang awalnya dari mulut ke mulut sambil menunjukan akun Instagram, komunikasi tersebut sangat efektif bagi para penjual, dengan adanya media Instagram semakin mudahnya penjual menunjukkan foto atau katalaog barang jualannya. Dalam hal ini secara tidak langsung proses tersebut membentuk suatu rangkaian komunikasi pemasaran dan menimbulkan perilaku konsumtif untuk berbelanja (Alharethi, 2016). 
Online shopping atau belanja online via internet, adalah suatu proses pembelian barang atau jasa melalui internet. Sejak kehadiran internet, para pedagang telah berusaha membuat toko online dan menjual produk kepada mereka yang sering menjelajahi dunia maya (internet) melalui berbagai macam media sosial, blog, bahkan web (Alharethi, 2016). Berbisnis melalui internet memberikan kemudahan tersendiri bagi penjual maupun pembeli, selain efisien dalam biaya iklan juga efektif dalam promosi karena masyarakat saat ini banyak mengandalkan online shop untuk berbelanja.

Tarasova (2015) mengemukakan kelebihan spesifik online shop menggunakan media Instagram adalah pasar yang melek teknologi. Salah satu kelebihan berjualan lewat Instagram adalah pengguna Instagram sudah melek teknologi. Artinya, mereka yang aktif di Instagram pastilah aktif pula di Twitter dan mungkin juga Facebook. Oleh karena itu, sangat tepat bila mempromosikan produk melalui Instagram dan dibantu jejaring sosial lainnya, pengguna Instagram pastilah memiliki gadget dan smartphone mahal yang mendukung aplikasi tersebut seperti iPhone, ini berarti Instagram memiliki pengguna yang rata-rata kelas menengah ke atas. Hal ini menguntungkan bagi penjual, karena calon konsumen/pembeli kemungkinan besar mempunyai uang lebih untuk belanja online (Amelina dan Zhu, 2016).

\section{Berdasarkan penjelasan tersebut maka hipotesis pertama yang diajukan adalah}

\section{H1: Pengaruh Instagram Online Store terhadap Perilaku Konsumtif}

Konformitas yang ada di kalangan mahasiswa berpengaruh terhadap perilaku konsumtifnya. Konformitas merupakan suatu tuntutan yang tidak tertulis dari kelompok teman sebaya terhadap anggotanya tetapi memiliki pengaruh yang kuat dan dapat menyebabkan munculnya perilakuperilaku tertentu pada anggota kelompok. Perilaku tertentu yang dimaksud dapat membentuk perilaku konsumtif pada mahasiswa (Zebua dan Nurdjayadi, 2001).

Rizkallah dan Truong (2010) mengemukakan aturan-aturan yang mengatur bagaimana individu seharusnya dan sebaiknya berperilaku disebut dengan norma sosial (social norms). Aturanaturan ini juga kerap kali memberikan efek yang kuat pada tingkah laku individu. Pada dasarnya ada beberapa norma sosial. Namun demikian, ada satu norma sosial yang berkaitan erat dengan konformitas, yaitu norma injungtif. Norma ini adalah suatu jenis norma yang memberi tahu kita mengenai apa yang seharusnya kita lakukan pada situasi-situasi tertentu.

Salah satu faktor yang mempengaruhi tingginya perilaku konsumtif adalah pengaruh kelompok referensi. Kelompok referensi memiliki pengaruh yang cukup kuat dalam membentuk kepribadian dan perilaku seseorang. Kelompok referensi digunakan sebagai alat untuk membandingkan dan mengevaluasi situasi individual. Rusich (2008) menjelaskan bahwa kelompok referensi memiliki pengaruh kuat karena merupakan tempat bagi individu untuk melakukan perbandingan nilai, informasi dan menyediakan petunjuk dalam melakukan konsumsi.

Berdasarkan penjelasan tersebut maka hipotesis kedua yang diajukan adalah

\section{H2: Pengaruh Konformitas terhadap Perilaku Konsumtif}

Iklan produk yang semakin gencar dan kreatif di televisi berpengaruh terhadap perilaku konsumtif mahasiswa. Reinartz dan Saffert (2013) meneliti tentang pengaruh kreativitas iklan terhadap efektivitas iklan. Sampel yang digunakan adalah 437 iklan televisi yang terdiri dari berbagai produk yang ditayangkan di televisi jerman. Indikator yang digunakan adalah originality, flexibility, elaboration, synthesis dan artistic value. Kesimpulan dari penelitian tersebut adalah kreativitas iklan berpengaruh positif terhadap efektivitas iklan.

Cobb et al. (1995) menemukan bahwa biaya belanja iklan berpengaruh positif terhadap ekuitas merek dan dimensi-dimensinya. Iklan memainkan peran penting dalam dunia yang 
kompetitif saat ini. Hal ini ditunjukkan dengan bagaimana organisasi berkomunikasi dengan pelanggan mereka, baik saat ini dan potensi di masa yang akan datang. Perusahaan mengalokasikan sebagian besar dari sumber-sumber mereka untuk kegiatan iklan (Ranjbarian et al., 2011).

Keinginan untuk membeli sesuatu ini biasa muncul dikarenakan melihat iklan di televisi dengan rayuan-rayuan iklan yang diberikan, ikut-ikutan teman yang mengikuti mode yang sedang berkembang, dan seringkali mementingkan gengsinya agar tidak ketinggalan zaman. Hal ini sejalan dengan pendapat Ranjbarian et al. (2011) meneliti tentang pengaruh efektivitas iklan terhadap minat pembelian. Sampel penelitian adalah iklan produk samsung di Iran dengan jumlah responden penelitian ini adalah 200 orang dengan metode random sampling. Kesimpulan dari penelitian ini adalah efektivitas iklan berpengaruh positif terhadap minat pembelian konsumen.

Berdasarkan penjelasan tersebut maka hipotesis ketiga yang diajukan adalah

\section{H3: Pengaruh Iklan Televisi terhadap Perilaku Konsumtif}

Perilaku konsumtif merupakan tindakan seorang membeli suatu barang tanpa adanya pertimbangan yang masuk akal dimana seorang tersebut dalam membeli suatu barangtidak didasarkan pada faktor kebutuhan (Enrico et al., 2014). Biasanya perilaku membeli barang tanpa pertimbangan ini hanya didorong oleh faktor rasa ketertarikan terhadap suatu barang. Perilaku konsumtif seseorang ialah perilaku yang tidak lagi membeli barang yang benar-benar dibutuhkan, tetapi membeli barang hanya sematamata untuk membeli dan mencoba produk, walau sebenarnya tidak memerlukan produk tersebut (Chen dan Whu, 2010).

Wahidah (2014) berpendapat bahwa perilaku konsumtif mahasiswa berpengaruh terhadap gaya hidup hedonis mahasiswa. Perilaku konsumtif tersebut membawa perubahan pada gaya hidup mahasiswa. Perilaku konsumtif mahasiswa yang yang mulai terbiasa lama kelamaan mulai menjadi kebiasaan yang menjadikan sebuah gaya hidup. Hal ini membawa mahasiswa ke dalam tindakan yang mementingkan penampilan luar mereka, harga diri mereka, serta bagaimana mengikuti perkembangan di lingkungan sekitar supaya setara.

Chen dan Whu (2010) menyatakan bahwa penting bagi pemasar untuk melakukan segmentasi pasar dengan mengidentifikasi gaya hidup melalui pola perilaku pembelian produk yang konsisten, penggunaan waktu konsumen, dan keterlibatannya dalam berbagai aktivitas. Chen dan Whu (2010) menegaskan bahwa gaya hidup merujuk pada bagaimana orang hidup, bagaimana mereka membelanjakan uangnya, dan bagaimana mereka mengalokasikan waktu mereka. Hal ini dinilai dengan bertanya kepada konsumen tentang aktivitas, minat, dan opini mereka, gaya hidup berhubungan dengan tindakan nyata dan pembelian yang dilakukan konsumen.

Kebiasaan ini menjadikan mereka sulit untuk bersikap rasional yang pada mulanya mahasiswa diharapkan mampu bertindak rasional dalam menyikapi perkembangna yang ada serta menjadikan mahasiswa tidak lagi berorientasi pad masa depan, justru berorientasi pada gaya hidup yang mereka jalani pada masa sekarang (Rizkallah dan Truong, 2010).

Berdasarkan penjelasan tersebut maka hipotesis keempat yang diajukan adalah

\section{H4: Pengaruh Perilaku Konsumtif terhadap Gaya Hidup Hedonis Mahasiswa}

Berikut ini adalah model penelitian yang akan dilakukan: 
Gambar 1. Kerangka Pemikiran Teoritis

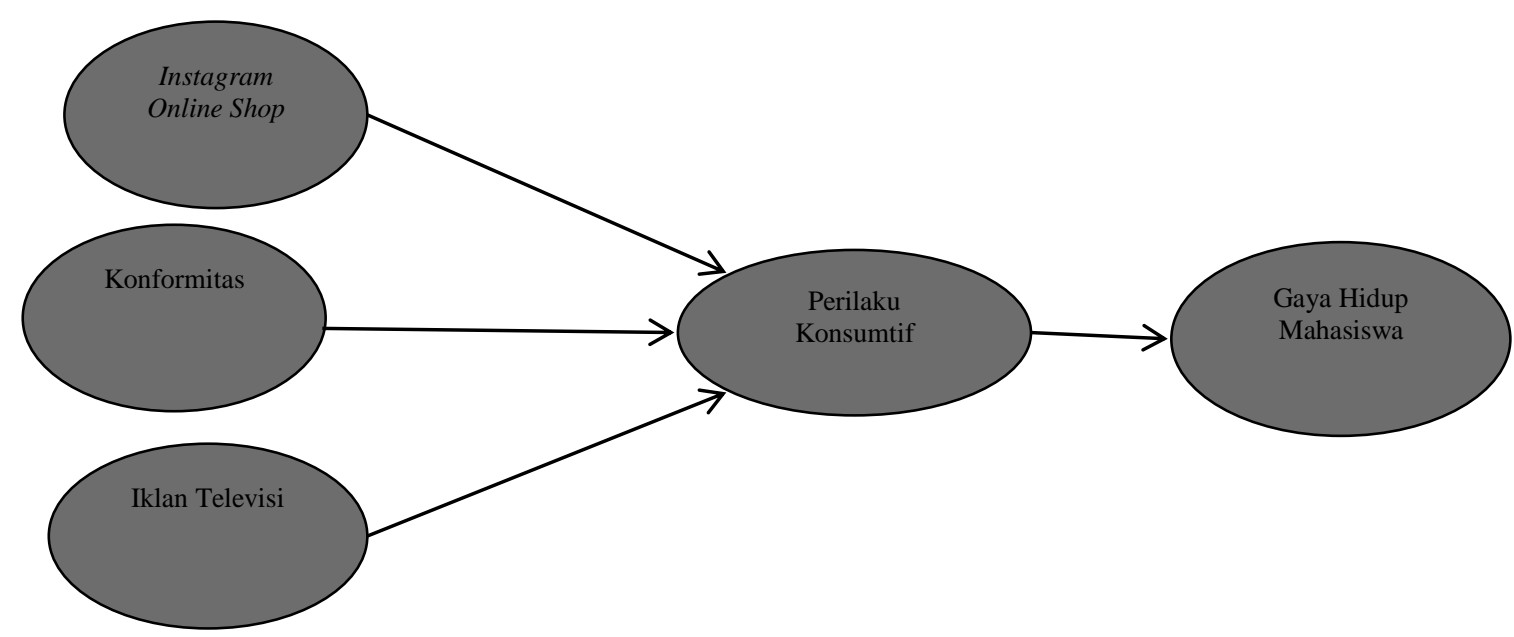

\section{METODE PENELITIAN}

Sumber data primer yang diperlukan dalam penelitian ini diperoleh dengan memberikan kuesioner secara langsung kepada responden. Iklan yang digunakan untuk sampel penelitian ini adalah semua iklan situs toko online yang ditayangkan di media televisi Indonesia, yaitu: berniaga.com, olx.co.id, tokopedia.com, elevania.com dan bukalapak.com.

Kriteria responden yang digunakan adalah mahasiswa pria dan wanita yang berusia antara 18-30 tahun. Pertimbangan dalam memilih subjek mahasiswa karena mereka tergolong dalam masyarakat menengah, kritis serta mampu memahami pesan-pesan iklan serta mampu memahami produk-produk yang berkaitan dengan sampel iklan tersebut.

Pada masa ini, mereka mulai bersikap kritis terhadap obyek-obyek di luar dirinya, dan mampu mengambil sintesis antara tanggapan tentang dunia luar dengan dunia intern atau kehidupan psikisnya sendiri (Sekaran, 2000). Sehingga diharapkan mampu memahami pertanyaan-pertanyaan yang terdapat dalam kuesioner dan diharapkan mampu memberikan jawaban yang dapat mewakili keadaan sebenarnya.

Penelitian ini mengambil sampel sebanyak 100 orang didasarkan pada pendapat Roscoe bahwa ukuran sampel lebih besar dari 30 dan kurang dari 500 telah mencukupi untuk digunakan dalam semua penelitian (Sekaran, 2000).

Metode pengambilan sampel adalah dengan metode non-probability sampling yaitu setiap unsur dalam populasi tidak memiliki kesempatan dan peluang yang sama untuk dipilih sebagai sampel. Pengambilan sampel dilakukan dengan purposive sampling yaitu pengambilan sampel dengan kriteria tertentu agar sampel yang diambil sesuai dengan tujuan penelitian.

Analisis data yang dilakukan dengan menggunakan the Structural Equation Model (SEM) dalam model dan pengujian hipotesis. SEM atau model persamaan structural adalah sekumpulan teknik-teknik statistikal yang memungkinkan pengujian sebuah rangkaian hubungan yang relatif rumit, secara simultan. Yang dimaksud dengan rumit adalah model-model simultan yang dibentuk melalui lebih dari satu variabel dependen pada saat yang sama berperan sebagai variabel independent bagi hubungan berjenjang lainnya.

Sebuah permodelan SEM yang lengkap pada dasarnya terdiri dari dua bagian utama yaitu Measurement Model dan Structural Model. Measurement Model atau model pengukuran untuk mengkonfirmasi indikator-indikator dari sebuah variabel laten serta model struktural yang menggambarkan hubungan kausalitas antar dua atau lebih variabel. Structural Model adalah model mengenai struktur hubungan yang membentuk atau menjelaskan kausalitas antara faktor. 
Terdapat tujuh langkah yang harus dilakukan apabila menggunakan permodelan Structural Equation Model (SEM), yaitu pengembangan model berdasar teori, pengembangan diagram alur (path diagram), konversi diagram alur ke dalam persamaan, memilih jenis input matrik dan estimasi model yang diusulkan, menilai problem identifikasi model struktural, menilai kriteria goodness of fit, melakukan interpretasi dan modifikasi model. Dalam penelitian ini, peneliti akan menggunkan SEM untuk melakukan pengujian hipotesis 1-4 diuji dengan path analysis, yaitu untuk mengetahui tingkat signifikansi antar variabel.

\section{Analisis Data dan Pembahasan}

Peneliti mengedarkan kuesioner dengan terjun langsung mendampingi responden dalam proses pengisian. Alasan Peneliti terjun langsung membagikan kuesioner kepada responden adalah untuk : 1) Memastikan bahwa responden yang ikut serta dalam penelitian ini sudah sesuai dengan kriteria yang dibuat, 2) Membantu responden dalam cara mengisi kuesioner, 3) Membantu responden dalam menterjemahkan arti dari item pertanyaan bila ada yang kurang jelas dari pertanyaan tersebut, 4) Mendapatkan tingkat respon $100 \%$.

Sebanyak 142 responden berpartisipasi dalam penelitian ini. Responden yang berpartisipasi adalah mahasiswa di yogyakarta. Pengumpulan data dilakukan secara langsung selama 20 hari. Tingkat respon responden dapat dilihat pada Tabel 1.

Tabel 1. Hasil Penyebaran Kuesioner

\begin{tabular}{|c|l|c|}
\hline No. & \multicolumn{1}{|c|}{ Keterangan } & Responden \\
\hline 1. & Kuesioner yang disebar & 150 \\
\hline 2. & Kuesioner yang dikembalikan & 142 \\
\hline 3. & Tingkat respon & $94,7 \%$ \\
\hline & Total kuesioner yang dianalisis & 142 \\
\hline
\end{tabular}

Analisis demografi digunakan untuk mengetahui demografi profil responden. Dalam penelitian ini, responden diklasifikasikan berdasar pada jenis kelamin, usia, dan status pendidikan. Hasil analisis demografi dirangkum dalam tabel 2 sebagai berikut:

Tabel 2. Profil Responden Berdasarkan Jenis Kelamin

\begin{tabular}{|c|c|c|}
\hline Jenis Kelamin & Jumlah Responden & Persentase \\
\hline Pria & 61 & $42,96 \%$ \\
\hline Wanita & 81 & $57,04 \%$ \\
\hline Total & 142 & $100 \%$ \\
\hline
\end{tabular}

Berdasarkan Tabel 2 diperoleh hasil bahwa responden pria berjumlah 61 orang dengan persentase sebesar $42,96 \%$ dan responden wanita berjumlah 81 orang dengan persentase sebesar $57,04 \%$. Hal ini berarti responden wanita lebih banyak berpartisipasi dalam penelitian ini dibandingkan dengan responden pria. 
Tabel 3. Profil Responden Berdasarkan Usia

\begin{tabular}{|c|c|c|}
\hline Usia & Jumlah Responden & Persentase \\
\hline$<20$ tahun & 2 & $1,41 \%$ \\
\hline $20-22$ tahun & 54 & $38.03 \%$ \\
\hline $23-25$ tahun & 63 & $44.37 \%$ \\
\hline $26-30$ tahun & 21 & $14.79 \%$ \\
\hline$>30$ tahun & 2 & $1.41 \%$ \\
\hline Total & 142 & $100 \%$ \\
\hline
\end{tabular}

Berdasarkan pada Tabel 3 diperoleh hasil bahwa usia responden didominasi oleh usia 23-25 tahun dengan jumlah 63 orang dan persentase 44.37\%. Tertinggi kedua adalah usia 20-22 tahun dengan jumlah 54 orang dan persentase 38.03\%. Jumlah tersebut mengindikasikan bahwa responden didominasi oleh mahasiswa muda yang mempunyai akun social media dan kelompok referensi untuk pengambilan keputusan pembelian online.

Tabel 4. Profil Responden Berdasarkan Pendidikan

\begin{tabular}{|c|c|c|}
\hline Pendidikan Terakhir & Jumlah & Persentase \\
\hline D3 & 2 & $1.41 \%$ \\
\hline S1 & 110 & $77.47 \%$ \\
\hline S2 & 20 & $14.08 \%$ \\
\hline PPA & 10 & $7.04 \%$ \\
\hline Total & 142 & $100 \%$ \\
\hline
\end{tabular}

Berdasarkan hasil pengolahan data pada Tabel 4 ditemukan bahwa sebagian besar responden berpendidikan terakhir S1 dengan jumlah 110 orang dan persentase sebesar $77.47 \%$. Tertinggi kedua adalah responden dengan pendidikan S2, berjumlah 20 orang dan persentase sebesar $14.08 \%$. Fakta ini mengindikasikan bahwa responden didominasi oleh mahasiswa S1 dan S2.

Uji validitas digunakan untuk mengukur kemampuan skala yang digunakan untuk mengukur konsep yang dimaksud (Tjahjono,2015), tujuannya adalah untuk menguji komponen pertanyaan dalam kuesioner dan menjamin bahwa alat ukur yang digunakan cocok dengan objek yang diukur. Factor analysis dinyatakan valid jika Factor Loading $>0.5$.

Variabel independen dalam penelitian ini adalah gaya hidup mahasiswa. Item pertanyaan instagram online store digambarkan dalam IG1 s/d IG6. Nilai factor loading $>0.5$ sehingga semua valid. Item pertanyaan konformitas digambarkan dalam K1 s/d K7. Nilai factor loading > 0.5 sehingga semua valid. Item pertanyaan Iklan televisi digambarkan dalam TV1 s/d TV6. Nilai factor loading item pertanyaan K3, K5 Tidak valid. Item pertanyaan perilaku konsumtif digambarkan dalam P1 s/d P7. Nilai factor loading > 0.5 sehingga semua valid. Item pertanyaan gaya hidup hedonis mahasiswa digambarkan dalam G1 s/d G3. Nilai factor loading > 0.5 sehingga semua valid.

Uji reliabilitas digunakan untuk mengetahui sejauh mana hasil pengukuran tetap konsisten jika dilakukan dua kali atau lebih dengan alat ukur yang sama untuk gejala yang sama. Suatu 
kuesioner dikatakan reliabel atau handal jika jawaban seseorang terhadap pertanyaan adalah konsisten atau stabil dari waktu ke waktu. Salah satu cara untuk uji reliabilitas adalah dengan menghitung cronbach's alpha yang menunjukkan konsistensi dalam merespon keseluruhan komponen yang mewakili pengukuran suatu variabel.

Hasil output uji reliabilitas untuk variabel Instagram Online Store, Konformitas, Iklan Televisi, Perilaku Konsumtif dan Gaya Hidup Hedonis Mahasiswa dapat diringkas pada Tabel 5 berikut ini

Tabel 5. Hasil Uji Reliabilitas

\begin{tabular}{|l|c|l|}
\hline \multicolumn{1}{|c|}{ Variabel } & Cronbach alpha & Kategori \\
\hline Instagram Online Store & 0.820 & Reliabilitas baik \\
\hline Konformitas & 0.786 & Reliabilitas baik \\
\hline Iklan Televisi & 0.832 & Reliabilitas baik \\
\hline Perilaku Konsumtif & 0.894 & Reliabilitas baik \\
\hline Gaya Hidup Hedonis Mahasiswa & 0.814 & Reliabilitas baik \\
\hline
\end{tabular}

Statistik deskriptif digunakan untuk menggambarkan variabel variabel yang digunakan dalam penelitian berdasarkan pada kuesioner yang telah dikumpulkan oleh peneliti. Hasil pengujian korelasi antar variabel dalam Tabel 5 tidak ada yang menunjukkan adanya masalah multikolinearitas antar variabel independen, karena nilainya kurang dari 0.8. Hasil pengujian statistik deskriptif dirangkum pada Tabel 6.

Tabel 6. Statistik Deskriptif

\begin{tabular}{|c|c|c|c|c|c|c|c|}
\hline Variabel & Mean & $\begin{array}{c}\text { Std. } \\
\text { Deviasi }\end{array}$ & $\begin{array}{c}\text { Instagram } \\
\text { Online } \\
\text { Store }\end{array}$ & Konformitas & $\begin{array}{c}\text { Iklan } \\
\text { Televisi }\end{array}$ & $\begin{array}{c}\text { Perilaku } \\
\text { Konsumtif }\end{array}$ & $\begin{array}{c}\text { Gaya Hidup } \\
\text { Hedonis } \\
\text { Mahasiswa }\end{array}$ \\
\hline $\begin{array}{l}\text { Instagram } \\
\text { Online Store }\end{array}$ & 3.894 & 0.323 & 1 & $0.312^{* *}$ & $0.470^{* *}$ & $0.730^{* *}$ & $0.583^{* *}$ \\
\hline Konformitas & 4.230 & 0.441 & - & 1 & $0.324^{* *}$ & $0.431^{* *}$ & $0.297^{* *}$ \\
\hline Iklan Televisi & 3.342 & 0.424 & - & - & 1 & $0.458^{* *}$ & $0.434^{* *}$ \\
\hline $\begin{array}{l}\text { Perilaku } \\
\text { Konsumtif }\end{array}$ & 3.898 & 0.416 & - & - & - & 1 & $0.786^{* *}$ \\
\hline $\begin{array}{l}\text { Gaya Hidup } \\
\text { Hedonis } \\
\text { Mahasiswa }\end{array}$ & 3.903 & 0.425 & - & - & - & - & 1 \\
\hline
\end{tabular}

** Menunjukkan korelasi yang signifikan pada tingkat 0.01

Nilai rata-rata instagram online store sebesar 3.894 menunjukkan bahwa, rata-rata responden menilai instagram online store sudah banyak diketahui dan digemari oleh mahasiswa. Nilai rata-rata konformitas sebesar 4.230 menunjukkan bahwa, rata-rata responden menilai 
memiliki kelompok referensi dalam memutuskan pembelian produk. Nilai rata-rata Iklan Televisi sebesar 3.342 menunjukkan bahwa, rata-rata responden menilai menilai iklan tersebut kreatif. Nilai rata-rata perilaku konsumtif sebesar 3.898 menunjukkan bahwa, rata-rata responden menyadari memiliki perilaku konsumtif. Terakhir, nilai rata-rata gaya hidup hedonis mahasiswa sebesar 3.903 menunjukkan bahwa, rata-rata responden menilai muncul gaya hidup hedonis mahasiswa yang tinggi setelah melihat online store.

Nilai GFI (Goodness of Fit) sebesar 0.857. Nilai GFI yang baik adalah yang mendekati angka 1, jadi nilai kesesuaian model dengan data dalam penelitian ini dapat dikatakan cukup baik. Nilai CFI (Comparative Fit Index) sebesar 0.828 Nilai CFI yang baik adalah yang mendekati angka 1 , jadi nilai kesesuaian model dengan data dalam penelitian ini dapat dikatakan cukup baik.

Tabel 7. Hasil Pengujian Model Fit

\begin{tabular}{|c|c|c|c|}
\hline Goodness-of-fit Index & Kriteria & Hasil Olah Data & Evaluasi Model \\
\hline Chi Square & Kecil, tidak signifikan & 38.9, Sig & Kurang Baik \\
\hline CMIN/DF & $\begin{array}{c}1-2 \text { over fit, } 2-5 \text { liberal } \\
\text { limit }\end{array}$ & 6.488 & Cukup baik \\
\hline GFI & $<1$ & 0.897 & Baik \\
\hline AGFI & $>0,80$ & 0.684 & Cukup Baik \\
\hline TLI & $>0,9$ & 0.742 & Cukup baik \\
\hline CFI & $>0,9$ & 0,819 & Cukup Baik \\
\hline RMSEA & $<0,08$ upper limit $<0,1$ & 0,221 & Kurang baik \\
\hline
\end{tabular}

Nilai GFI (Goodness of Fit) sebesar 0.897 Baik. Nilai TLI (Tucker Lewis Index) sebesar 0.742 cukup baik karena nilainya mendekati 1. Nilai AGFI (Adjusted Goodness of Fit) sebesar 0.684 sedikit memenuhi batas minimum di bawah 0.8. Nilai CMIN/DF berada di atas standar yaitu 6.488, dengan nilai batas maksimal adalah 5. Nilai RMSEA sebesar 0,221 dapat tidak memenuhi kriteria penerimaan model karena melebihi batas atas 0,1. Oleh karena kriteria pada Goodness of fit index lebih banyak kriteria yang baik dan cukup dibandingkan kriteria yang kurang baik, maka secara umum model fit dapat dikatakan cukup baik.

Hipotesis $\mathrm{H} 1, \mathrm{H} 2, \mathrm{H} 3, \mathrm{H} 4$, diuji dengan melihat significant path pada penelitian. Hasil pengujian hipotesis dapat terlihat pada Tabel 8.

Tabel 8. Hasil Pengujian Hipotesis

\begin{tabular}{|l|l|c|c|c|}
\hline No. & \multicolumn{1}{|c|}{ Isi Hipotesis } & $\begin{array}{c}\text { Standardized } \\
\text { Regression Weights }\end{array}$ & P & Keterangan \\
\hline H1 & $\begin{array}{l}\text { Instagram Online Store berpengaruh positif } \\
\text { terhadap perilaku konsumtif. }\end{array}$ & 0.220 & 0.013 & Hipotesis diterima \\
\hline H2 & $\begin{array}{l}\text { Konformitas berpengaruh positif terhadap } \\
\text { perilaku konsumtif. }\end{array}$ & 0.728 & $<0.001$ & Hipotesis diterima \\
\hline
\end{tabular}




\begin{tabular}{|l|l|c|c|c|}
\hline H3 & $\begin{array}{l}\text { Iklan televisi Tidak berpengaruh terhadap } \\
\text { perilaku konsumtif. }\end{array}$ & 0.970 & 0.095 & Hipotesis ditolak \\
\hline H4 & $\begin{array}{l}\text { perilaku konsumtif berpengaruh positif terhadap } \\
\text { gaya hidup hedonis mahasiswa }\end{array}$ & 0.825 & $<0.001$ & Hipotesis diterima \\
\hline
\end{tabular}

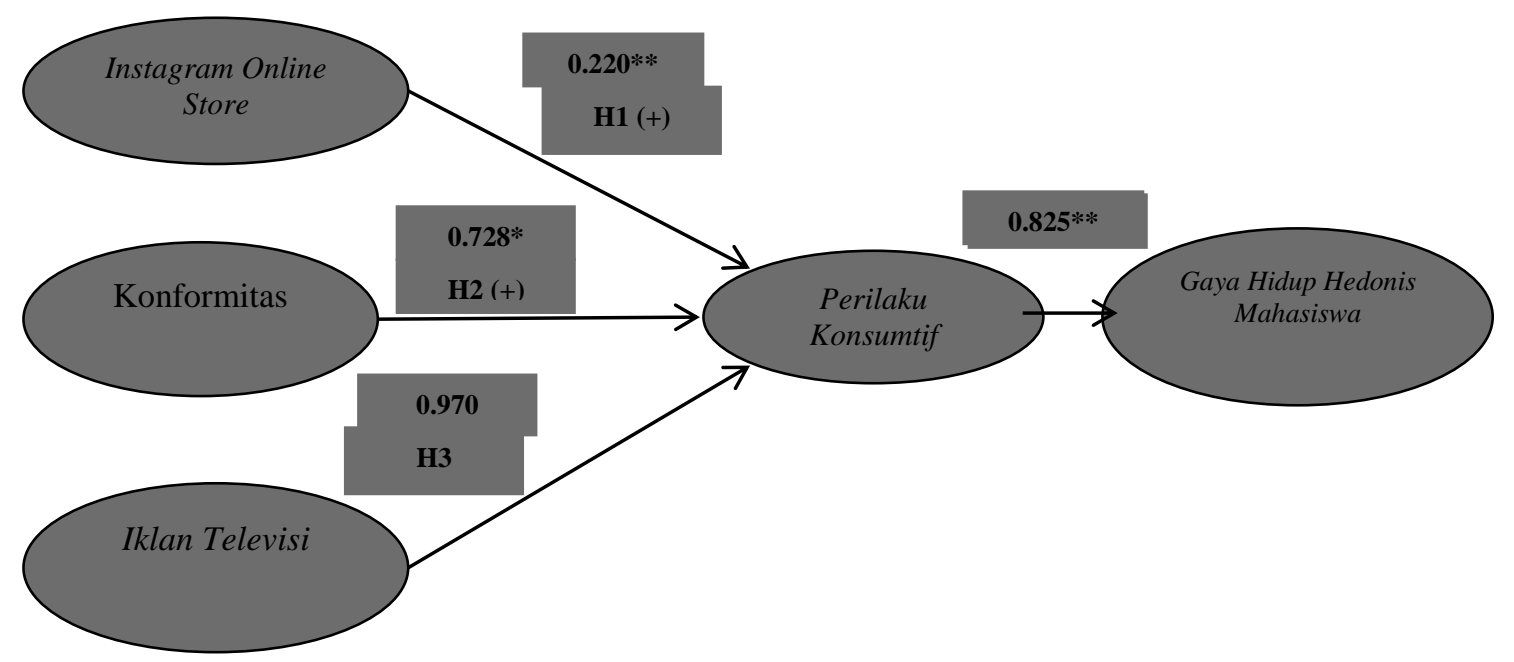

Keterangan: * Signifikan pada $\mathrm{P}<0.05$

** Signifikan pada $\mathrm{P}<0.01$

Pada Tabel 7 ditemukan bahwa instagram online store berpengaruh positif terhadap perilaku konsumtif $(\beta=0.220, \mathrm{P}<0,05)$. Hasil analisis ini mendukung hipotesis pertama. konformitas berpengaruh positif terhadap perilaku konsumtif $(\beta=0.728, \mathrm{P}<0.05)$. Hasil analisis ini mendukung hipotesis kedua. Iklan Televisi tidak berpengaruh terhadap perilaku konsumtif $(\beta=0.970, \mathrm{P}>0,05)$. Hasil ini tidak mendukung hipotesis ketiga. Advertising effectiveness berpengaruh positif terhadap online shopping intention $(\beta=0.810, \mathrm{P}<0,1)$. Hasil ini mendukung hipotesis keempat.

Tidak terlihatnya pengaruh antara iklan televisi terhadap perilaku konsumtif diduga era yang berkembang sekarang menunjukkan mahasiswa beralih ke komunikasi sosial media. Iklan televisi mulai tersisihkan dan tidak terlalu berpengaruh terhadap perilaku konsumtif mahasiswa. Selain itu, pemilihan usia responden (mahasiswa) mungkin sudah tidak terlalu terpengaruh terhadap iklan televisi jika dibandingkan dengan usia anak-anak yang masih membentuk perilaku konsumtif pada usia dini sehingga mudah terpengaruh iklan televisi.

\section{KESIMPULAN DAN SARAN}

Penelitian ini membuktikan adanya pengaruh instagram online store, konformitas terhadap perilaku konsumtif dan dampaknya terhadap gaya hidup hedonis mahasiswa. Variabel iklan televisi tidak berpengaruh terhadap perilaku konsumtif. Tidak terlihatnya pengaruh antara iklan televisi terhadap perilaku konsumtif diduga era yang berkembang sekarang menunjukkan mahasiswa beralih ke komunikasi sosial media. Iklan televisi mulai tersisihkan dan tidak terlalu berpengaruh terhadap perilaku konsumtif mahasiswa. Selain itu, pemilihan usia responden (mahasiswa) mungkin sudah tidak terlalu terpengaruh terhadap iklan televisi jika dibandingkan dengan usia anak-anak yang masih membentuk perilaku konsumtif pada usia dini sehingga mudah terpengaruh iklan televisi. 
Keterbatasan dari penelitian ini adalah jumlah sampel yang masih terbatas, sehingga berpengaruh pada hasil uji statistik yang dilakukan. Selain itu, keterbatasan ruang lingkup sampel yang masih sempit. Penelitian ini hanya mengambil sampel dari latar belakang organisasi pendidikan. Pada penelitian mendatang, perlu ditambahkan sampel dari organisasi dengan latar belakang yang lebih bervariasi agar memperkaya data dan hasil yang dapat diolah. Beberapa saran penelitian mendatang adalah penambahan jumlah variabel yang dapat melihat model dengan lebih utuh, penambahan variasi latar belakang organisasi, dan menambah jumlah sampel yang mencukupi untuk dapat memenuhi persyaratan dalam penggunaan analisis SEM.

Penelitian mendatang diharapkan dapat memperbaiki instrumen untuk variabel iklan televisi agar item pertanyaan kuesioner semua valid. Menambahkan variabel lain yang dapat membentuk gaya hidup hedonis mahasiswa seperti variabel media iklan, durasi iklan, pesan iklan dan lain-lain. Selain itu, diharapkan sebaran kuesioner semakin luas dan tidak hanya kalangan mahasiswa tetapi masyarakat umum dilibatkan dalam penelitian.

Hasil-hasil dari penelitian ini beserta berbagai keterbatasannya agar dapat dijadikan sumber ide dan masukan bagi pengembangan penelitian khususnya yang terkait pada bidang perilaku konsumen dan marketing. Selain itu, dapat dijadikan bahan referensi bagi dunia praktis perusahaan.

\section{DAFTAR PUSTAKA}

Alharethi, M. A. (2016). Using Instagram for shopping in Saudi Arabia (Doctoral dissertation, Arkansas State University).

Amelina, D., \& Zhu, Y. Q. (2016). Investigating Effectiveness of Source Credibility Elements on Social Commerce Endorsement: The Case of Instagram in Indonesia.

Che, J. W., Cheung, C. M., \& Thadani, D. R. (2017, January). Consumer Purchase Decision in Instagram Stores: The Role of Consumer Trust. In Proceedings of the 50th Hawaii International Conference on System Sciences.

Chen, W. Y., \& Wu, P. H. (2010, October). Factors affecting consumers' motivation in online group buyers. In Intelligent Information Hiding and Multimedia Signal Processing (IIH-MSP), 2010 Sixth International Conference on (pp. 708-711). IEEE.

Cobb-Walgren, Cathy. J., Beal.C., Donthu.N. (1995). "Brand Equity, Brand Preferences, and Purchase Intent." Journal of Advertising 24 (3): 25-40.

Enrico, A., Aron, R., \& Oktavia, W. (2014). The factors that influenced consumptive behavior: a survey of university students in Jakarta. International Journal of Scientific and Research Publications, 4(1).

Hausman, A. V., \& Siekpe, J. S. (2009). The effect of web interface features on consumer online purchase intentions. Journal of Business Research, 62(1), 5-13.

Henningsen, Sina, Heuke, Rebecca, Clement, Michel. (2011). Determinants of Advertising Effectiveness: The Development of an International Advertising Elasticity Database and a Meta-Analysis. BuR Business Research Journal, Vol. 4, No. 2, pp. 193-239.

Kotler, P., \& Keller, K. L. (2009). Dirección de marketing. Pearson educación.

Lowrey, Tina M, Shrum, L. J, McCarty, John A. (2010). The Future of Television Advertising. Journal of Consumer Affairs.

O'Brien, K. M. (2016). Effects of Consumer Socialization through Instagram on Purchasing Intentions and Brand Perceptions: A Systematic Literature Review. 
Putri, J. W. (2015). Factors Affecting Customers Online Search Intention and Online Purchase Intention using Social Networks: Case Study of Online Shop on Instagram. iBuss Management, 3(2).

Ranjbarian, Bahram, Abdollahi, Sayedeh Masoomeh, Khorsandnejad, Arezoo. (2011). The Impact of Brand Equity on Advertising Effectiveness (Samsung and Snowa brand names as a case study). Interdisciplinary Journal Of Contemporary Research In Business Vol 3, No 5.

Reinartz, Werner and Peter Saffert, Peter. (2013). Creativity in Advertising: When It Works and When It Doesn't. Harvard Business Review.

Rizkallah, E. G., \& Truong, A. (2010). Consumptive behavior, promotional preferences, and shopping patterns of Hispanic Americans: an empirical perspective. Journal of Business \& Economics Research, 8(4), 111.

Rusich, E, A. (2008). Departement Of Psychology Loyola University New Orlean : The Relationship Beetween Conformity And Consumer Purchasing Decision. Journal of Consumer Research. Published by Missouri : Missouri Western State University.

Schiffman \& Kanuk. (2004). Perilaku Konsumen. Edisi Ketujuh. Diterjemahkan oleh Drs. Zoelkifli Kasip. Jakarta : PT Indeks.

Sekaran, U. 2000. Research Methods for Business: A Skill Building Approach, $3^{\text {rd }}$ ed., New York: John Wiley \& Sons, Inc.

Tarasova, E. (2015, June). Instagraming in Russia. In 2015 Global Fashion Management Conference at Florence (pp. 187-188).

Tjahjono, H.K. (2015). Metode Penelitian Bisnis. VSM. MM UMY.

Wahidah, N. (2014). Pengaruh Perilaku Konsumtif Terhadap Gaya Hidup Mahasiswa Pendidikan Ekonomi Fkip UNTAN. Jurnal Pendidikan dan Pembelajaran, 3(2).

Zadmehr, S., Fatourehchi, S., \& Zadmehr, H. (2016). Identifying and Structuring Factors Affecting the Purchase from Mobile Social Networks (Case Study: Instagram Application). International Journal of Life Sciences, 10(2), e115-e127.

Zebua, A \& Nurdjayadi, R. (2001). Hubungan Antara Konformitas dan Konsep Diri Dengan Perilaku Konsumtif Pada Remaja Putri. Jurnal Phronesis. 3, 6, 72-82. 